\title{
What do patients with psychotic and mood disorders know about their illness and medication?
}

C Kotzé, MB ChB, DMH (SA), FC (Psych), MMed (Psych) M P King, MB ChB, MMed (Psych)

P M Joubert, MB ChB, MMed (Psych), FC (Psych)

Weskoppies Hospital, Pretoria

While there are several papers on psychoeducation in the literature, there is a paucity of publications on patients' knowledge of their diagnosis and treatment. The overall management of psychiatric patients includes informing them about their diagnosis and treatment, as part of their psychoeducation. Psychoeducation can be defined as the education of a person with a psychiatric disorder about their diagnosis and treatment to assist the goals of treatment and rehabilitation, ${ }^{2}$ i.e. to increase patients' knowledge about, and insight into, their illness and its treatment. This knowledge enables them to cope more effectively with their disorder, thereby improving their prognosis.

According to Pekkala and Merinder, authors of the 2006 Cochrane review on psychoeducation for schizophrenia, any kind of psychoeducational intervention significantly decreased relapse or readmission rates at $9-18$ months' follow-up compared with standard care. Findings were also consistent with the probability that psychoeducation had a positive effect on a person's well-being. It is estimated that about 12 relapses can be avoided, or at least postponed for around a year, for every 100 patients who receive psychoeducation. There is some suggestion that psychoeducation may improve compliance with medication, but the extent of improvement remains unclear.'

In patients with a bipolar disorder, psychoeducation has been shown to enhance adherence to treatment. Training in identifying early manic symptoms helps to improve outcomes and decreases the number of manic relapses. ${ }^{26}$ A small study involving 57 patients showed improvement in quality of life in patients who receive psychoeducation.

Family psychoeducation in adolescent major depressive disorder has been shown to have positive effects on family and social functioning processes, and is postulated to improve the clinical course of major depressive disorder. ${ }^{8}$

The only article found on patients' knowledge of their diagnosis was published in 1998 by the Institute of Psychiatry in London.
The authors found that patients with schizophrenia were less likely to have been informed of their diagnosis than patients with mood or anxiety disorders. Most patients wanted to know their diagnosis, and most agreed with their diagnosis and its usefulness. The authors suggested that all patients should be asked whether they want to know their diagnosis, and must then be informed appropriately. ${ }^{9}$ In the present study, we too wished to evaluate the knowledge that psychiatric patients have of their diagnosis and treatment.

\section{Objectives}

The aim of the study was to explore the extent of the knowledge of their diagnosis and treatment of patients attending the Outpatient Department of Weskoppies Hospital, who had a diagnosis of a psychotic and/or mood disorder.

\section{Method}

This clinically descriptive study was conducted at the Outpatient Department of Weskoppies Hospital. Subjects $>18$ years suffering from psychotic and mood disorders were recruited prospectively. This was done on the days that the first two researchers were scheduled to deliver a clinical service at the Outpatient Department during the period July - October 2006. The researchers had no influence on which subjects were assigned to them for the consultation, since that was the usual function of the administrative personnel at the hospital.

Only subjects who were able to give informed consent, who gave informed consent, and who consulted with one of the two researchers for the first time after the study had commenced, were included in the study. Interviews were conducted in English and Afrikaans without an interpreter. The Ethics Committee of the Faculty of Health Sciences, University of Pretoria, approved the study protocol. Approval was also obtained from the Chief Executive Officer of Weskoppies Hospital for conducting the study and for accessing information in terms of the Promotion of Access to Information Act, No. 2 of 2000.

\section{Data captured}

The following data were obtained from the subjects' clinical files: diagnosis of Axis I disorders according to DSM-IV; the first time 
that the diagnosis had been made; the number of co-morbid Axis I disorders; the class of prescribed medication for the mental illness; age; race; and gender. The number of subjects who were approached and those who declined to participate were also noted.

The subjects were interviewed in a semi-structured way by asking them the following questions:

- Do you know your diagnosis?

- Do you know what it means?

- Do you know what medication you are on?

- Do you know what the medication is for?

- Do you know what the side-effects of the medications are?

We considered subjects to know their diagnoses even if they did not know the exact names of the diagnoses but knew which clinical phenomena they had been treated for. The diagnoses were categorised in three groups: bipolar disorders; depressive disorders; and psychotic disorders. The medications were grouped as: classic antipsychotic; novel antipsychotic; mood stabiliser; antidepressant (and class of antidepressant); sedative hypnotic; beta-blocker; anticholinergic; and other.

\section{Demographic profile}

There were 98 participants of whom 56 (57\%) were white, 39 (40\%) black, 2 (2\%) Indian, and 1 (1\%) coloured. There were 50 (51\%) males and 48 (49\%) females. Two patients declined to take part in the study. The ages of participants ranged from 19 to 78 years, with a standard deviation (SD) of 12 years and a median of 40 years. Fiffeen participants had only primary level education and 10 had tertiary level education, with the balance having secondary level education; none of the subjects was illiterate.

\section{Statistical analysis}

The Department of Information Technology at the University of Pretoria assisted in the data processing and statistical analysis. Fisher's exact test and the chi-square test were used for categorical data and variables.

\section{Results}

The duration of the subjects' treatment ranged from 6 months to 50 years. The average duration of treatment was 9.3 years, with a SD of 9.2 years. The diagnostic groups were as follows: psychotic disorders: 49 (50\%), bipolar disorders: 22 (22\%), and depressive disorders: 27 (26\%).
All the subjects had poor knowledge of drug side-effects. Twentyeight subjects (29\%) knew only the side-effects that they had experienced. Nineteen subjects (19\%) gave adequate answers to all study questions except for knowledge of side-effects. They knew their diagnoses, the meaning of their diagnoses, their drug treatment and the purposes of the drugs. Twenty-four (25\%) subjects answered all study questions inadequately; they knew neither their diagnoses nor the indications for their treatment nor the names of their medications. The remaining 55 (56\%) subjects knew or understood their diagnoses and treatment to some extent, as is summarised in Table I.

\section{Knowledge of diagnosis}

Subjects with a mood disorder were more likely to know their diagnosis than subjects with a psychotic disorder. There was a significant statistical association ( $p=0.094)$ between diagnosis of a psychotic disorder and diagnosis of a mood disorder, and knowing the diagnosis. There was no significant statistical association ( $p=0.12)$ between diagnostic group and knowing what the diagnosis meant. The knowledge that subjects had of their diagnoses and what their diagnoses meant, per diagnostic groups, is summarised in Table $\|$.

To evaluate whether having more than one co-morbid Axis I diagnosis influenced the extent of subjects' knowledge, we recorded the number of Axis I diagnoses that subjects had. Seventy-seven (79\%) subjects had only 1 diagnosis; of these, 44 (45\%) knew the diagnosis while 39 (40\%) knew what they were being treated for.

Twenty-one (21\%) subjects had >1 diagnosis. One (1\%) subject knew all the diagnoses and their meanings. Eleven (11\%) knew 1 diagnosis, and $10(10 \%)$ knew the meaning of the diagnosis. Nine (9\%) knew no diagnosis; 11 (11\%) did not know what they were being treated for.

\section{Knowledge of medication}

The results indicate that the more drugs a subject was receiving, the less likely they were to know the names of the drugs and their purpose. There was a significant association ( $p=0.0263$ ) between medication category and knowing the purpose of the medication. Subjects using antipsychotics were less likely to know what their medication was for than subjects in the other medication categories. The extent of the knowledge of subjects taking certain categories of medication of the names of the medication and the reasons for taking the medication is summarised in Table III. 


\begin{tabular}{|c|c|c|c|c|c|}
\hline Know diagnosis & $\begin{array}{l}\text { Know meaning of } \\
\text { diagnosis }\end{array}$ & Know medication & $\begin{array}{l}\text { Know indication for } \\
\text { medication }\end{array}$ & $N$ & $\%$ \\
\hline No & No & No & No & 24 & 25 \\
\hline No & No & No & Yes & 1 & 1 \\
\hline No & No & Yes & No & 10 & 10 \\
\hline No & No & Yes & Yes & 8 & 8 \\
\hline No & Yes & No & No & 4 & 4 \\
\hline No & Yes & No & Yes & 1 & 1 \\
\hline No & Yes & Yes & No & 4 & 4 \\
\hline No & Yes & Yes & Yes & 1 & 1 \\
\hline Yes & No & No & No & 3 & 3 \\
\hline Yes & No & No & Yes & 3 & 3 \\
\hline Yes & No & Yes & No & 5 & 5 \\
\hline Yes & No & Yes & Yes & 4 & 4 \\
\hline Yes & Yes & No & No & 4 & 4 \\
\hline Yes & Yes & No & Yes & 2 & 2 \\
\hline Yes & Yes & Yes & No & 5 & 5 \\
\hline Yes & Yes & Yes & Yes & 19 & 19 \\
\hline
\end{tabular}

\section{Table II. Diagnostic group and knowledge of diagnosis}

\begin{tabular}{|c|c|c|c|c|c|c|c|c|c|}
\hline \multirow[b]{2}{*}{ Diagnostic group } & \multirow{2}{*}{$\begin{array}{l}\text { Total in diag- } \\
\text { nostic group }\end{array}$} & \multicolumn{2}{|c|}{$\begin{array}{l}\text { Know name of } \\
\text { diagnosis }\end{array}$} & \multicolumn{2}{|c|}{$\begin{array}{l}\text { Do not know name } \\
\text { of diagnosis }\end{array}$} & \multicolumn{2}{|c|}{$\begin{array}{l}\text { Know what } \\
\text { diagnosis means }\end{array}$} & \multicolumn{2}{|c|}{$\begin{array}{l}\text { Do not know } \\
\text { what diagno- } \\
\text { sis means }\end{array}$} \\
\hline & & $N$ & $\%$ & $N$ & $\%$ & $N$ & $\%$ & $N$ & $\%$ \\
\hline Psychotic disorder & 49 & 15 & 31 & 34 & 69 & 15 & 31 & 34 & 69 \\
\hline Bipolar disorder & 22 & 14 & 64 & 8 & 36 & 11 & 50 & 11 & 50 \\
\hline Depressive disorder & 27 & 16 & 59 & 11 & 41 & 14 & 52 & 13 & 48 \\
\hline
\end{tabular}

There is a significant statistical association between diagnostic group and knowing the name of the medication ( $p=0.0492$ ), i.e. subjects with a mood disorder were more likely to know the name of their medication than subjects with a psychotic disorder. There was a significant statistical association between diagnostic group and knowing what the medication was for $(p=0.0083)$. Subjects with a mood disorder were more likely to know what the medication was for, compared with subjects with a psychotic disorder. Table IV summarises the association between diagnostic group and knowledge of medication.

\section{Discussion}

Our study explored the knowledge and understanding that patients had of their diagnoses as well as of the therapeutic and side-effects of the drugs used in treating their disorder. As has been shown, only 19\% overall could answer correctly all questions regarding their diagnosis and treatment as measured against information recorded in the clinical files, while as many as $24 \%$ did not answer any questions correctly. The remaining 56\% had varying degrees of knowledge and understanding of their diagnoses and treatment.

As indicated in the results, subjects with a mood disorder were somewhat more likely to know the names of their diagnoses than those with a psychotic disorder $(p=0.094)$. This finding is in keeping with that of Shergill et al. ${ }^{9}$

Although we did not investigate the reasons for patients' not knowing and understanding their diagnosis and treatment, we can suggest a number of possibilities. Learning might have been compromised by the way in which the information was given; for example, use of difficult terminology, language problems, and cultural differences. Subjects themselves may have difficulty retaining information given to them during psychoeducation owing to, for example, various forms of psychopathology (e.g. concentration difficulties) and drug side-effects (e.g. impaired concentration, interference with memory formation). Lack of insight can also be a contributory factor; a patient may remember the name of the diagnosis but does not accept it and is unwilling 
Table III. Medication category and knowledge related to it

\begin{tabular}{|c|c|c|c|c|c|c|c|c|c|}
\hline \multirow[b]{2}{*}{ Medication category } & \multirow{2}{*}{$\begin{array}{l}\text { Total on } \\
\text { medication } \\
\text { category }\end{array}$} & \multicolumn{2}{|c|}{$\begin{array}{l}\text { Know name of } \\
\text { medication }\end{array}$} & \multicolumn{2}{|c|}{$\begin{array}{l}\text { Do not know name } \\
\text { of medication }\end{array}$} & \multicolumn{2}{|c|}{$\begin{array}{l}\text { Know reason for } \\
\text { medication }\end{array}$} & \multicolumn{2}{|c|}{$\begin{array}{l}\text { Do not know } \\
\text { reason for } \\
\text { medication }\end{array}$} \\
\hline & & $N$ & $\%$ & $N$ & $\%$ & $N$ & $\%$ & $N$ & $\%$ \\
\hline Antipsychotics & 80 & 55 & 69 & 25 & 31 & 30 & 38 & 50 & 59 \\
\hline Mood stabilisers & 55 & 42 & 76 & 13 & 24 & 30 & 55 & 25 & 45 \\
\hline Antidepressants & 57 & 42 & 74 & 15 & 26 & 34 & 60 & 23 & 40 \\
\hline Anxiolytics & 16 & 12 & 75 & 4 & 25 & 9 & 56 & 7 & 44 \\
\hline Hypnotics & 22 & 16 & 73 & 6 & 27 & 15 & 68 & 7 & 32 \\
\hline For side-effects & 59 & 36 & 61 & 23 & 39 & 24 & 60 & 35 & 59 \\
\hline
\end{tabular}

\section{Table IV. Diagnostic group and knowledge of medication}

\begin{tabular}{|c|c|c|c|c|c|c|c|c|c|}
\hline \multirow[b]{2}{*}{ Diagnostic group } & \multirow{2}{*}{$\begin{array}{l}\text { Total in } \\
\text { diagnostic } \\
\text { group }\end{array}$} & \multicolumn{2}{|c|}{$\begin{array}{l}\text { Know name of } \\
\text { medication }\end{array}$} & \multicolumn{2}{|c|}{$\begin{array}{l}\text { Do not know name } \\
\text { of medication }\end{array}$} & \multicolumn{2}{|c|}{$\begin{array}{l}\text { Know what } \\
\text { medication is for }\end{array}$} & \multicolumn{2}{|c|}{$\begin{array}{l}\text { Do not know } \\
\text { what medica } \\
\text { tion is for }\end{array}$} \\
\hline & & $N$ & $\%$ & $N$ & $\%$ & $N$ & $\%$ & $N$ & $\%$ \\
\hline Psychotic disorder & 49 & 22 & 45 & 2 & 55 & 12 & 24 & 37 & 76 \\
\hline Bipolar disorder & 22 & 15 & 68 & 7 & 32 & 12 & 55 & 10 & 45 \\
\hline Depressive disorder & 27 & 19 & 70 & 8 & 30 & 15 & 56 & 12 & 44 \\
\hline
\end{tabular}

to give that diagnosis as an answer. Last but not least, some patients simply may not be interested in knowing more about their diagnosis and treatment. Therefore, they may neither feel a need to attend to information they are given nor try to remember it.

The fact that some patients knew what they were being treated for without knowing the name of the diagnosis also needs explanation. We offer the following possibilities: the unacceptability of certain diagnoses (e.g. of schizophrenia) may explain why patients with psychotic disorders knew what they were being treated for (e.g. for 'voices'), without having known (or having accepted) the term for the disorder. The other possibilities are the same as given in the previous paragraph.

We also suggest a reason why significantly more subjects (57\%) knew the names of their medication than why they are taking it (40\%): subjects were more often exposed to the name of the medication /seen on the dispensed drug containers, hearing their doctors and nurses mentioning the names of the medicines, being asked by others what medication they were on, etc.). Knowing what the medication was for might very well have been adequately explained previously, but it was not repeated in the same way that the names of the drugs were repeated. Another possibility is that subjects might have taken medications under some form of pressure, without accepting the diagnosis or the need for the medication.
If our proposed reasons are correct, we suggest the following measures to try to improve patients' inadequate knowledge and understanding of their diagnosis. Informing patients about their diagnosis and what it means should not be a once-off event; it should be repeated during the course of hospital stay and during outpatient follow-up. As part of such ongoing education, there could be visits during which patients are tested on their knowledge and understanding of the diagnosis and treatment, e.g. by asking patients what their diagnoses are; what they understand the diagnoses to mean; the course of their mental illness; what medication they receive; what the medication is for; and possible side-effects of the medication.

The main limitation of the study was that the investigators accepted the diagnoses in the clinical files as correct. Review or confirmation of diagnoses was beyond the scope of the study. Another possible limitation was that the degree to which patients understood their diagnosis and treatment was based on the judgement of the first two authors. On the other hand, both authors were senior registrars in psychiatry at the time of the study, and both had at least 4 years' experience in working with psychiatric patients at the time of the study. The absence of more detailed demographic data including participants' home language and cultural background is another limitation. This information might have complemented the postulated reasons for lack of knowledge. 


\section{Conclusion}

According to the findings of this study, there is considerable scope for improving the knowledge and understanding of our patients concerning their diagnoses and medication. There could be circumstances where patients would prefer not to have this knowledge, but the previously mentioned literature suggests that it can improve treatment adherence and long-term outcome.1.8 The fact that so many patients didn't know why they were taking medication is a plausible explanation for non-compliance and consequent relapse rates. It appears that patients with psychotic disorders, multiple diagnoses and who receive multiple drugs do need special psychoeducational attention.

In view of the limited scope of this study, it can only be viewed as a preliminary effort in this field. The exact reasons for deficiencies in patients' knowledge and understanding need further study in order to ascertain what can and should be done to improve the situation. We could not find literature that addresses this issue, but it remains the responsibility of the multidisciplinary team to inform patients about their diagnosis and treatment in a clear, understandable and persistent manner, whenever indicated.

\section{References}

1. Pekkala E, Merinder L. Psychoeducation for schizophrenia. Cochrane Database Syst Rev 2002 (accessed 3 August 2006)

2. Miklowitz DJ, George EL, Richards JA. A randomized study of family focused psychoeducation and pharmacotherapy in the outpatient management of bipolar disorder. Arch Gen Psychiatry 2003; 60(9): 904-912.

3. Colom F, Vieta E, Sanchez-Moreno J. Psychoeducation in bipolar patients with comorbid personality disorders. Bipolar Disord 2004; 6(4): 480-486.

4. Colom F, Lam D. Psychoeducation: improving outcomes in bipolar disorder. Eur Psychiatry 2005; 20(5-6): 359-364.

5. Machalak EE, Yatham LN, Wan DD. Perceived quality of life in patients with bipolar disorder. Does group psychoeducation have an impact? Can J Psychiatry 2005; 50(2): 95-100.

6. Colom F, Vieta E, Reinares M. Psychoeducation efficacy in bipolar disorders: beyond compliance enhancement. J Clin Psychiatry 2003; 64(9): $1101-1105$.

7. Vieta E. Improving treatment adherence in bipolar disorder through psychoeducation. J Clin Psychiatry 2005; 66 Suppl 1: 24-29

8. Sanford M, Boyle M, Mcleary L. A pilot study of adjunctive family psychoeducation in adolescent major depression: feasibility and treatment effect. J Am Acad Child Adolesc Psychiatry 2006; 45(4): 386-495.

9. Shergill SS, Barker D, Greeberg M. Communication of psychiatric diagnosis. Soc Psychiatry Psychiatr Epidemiol 1998; 33(1): 32-38. 